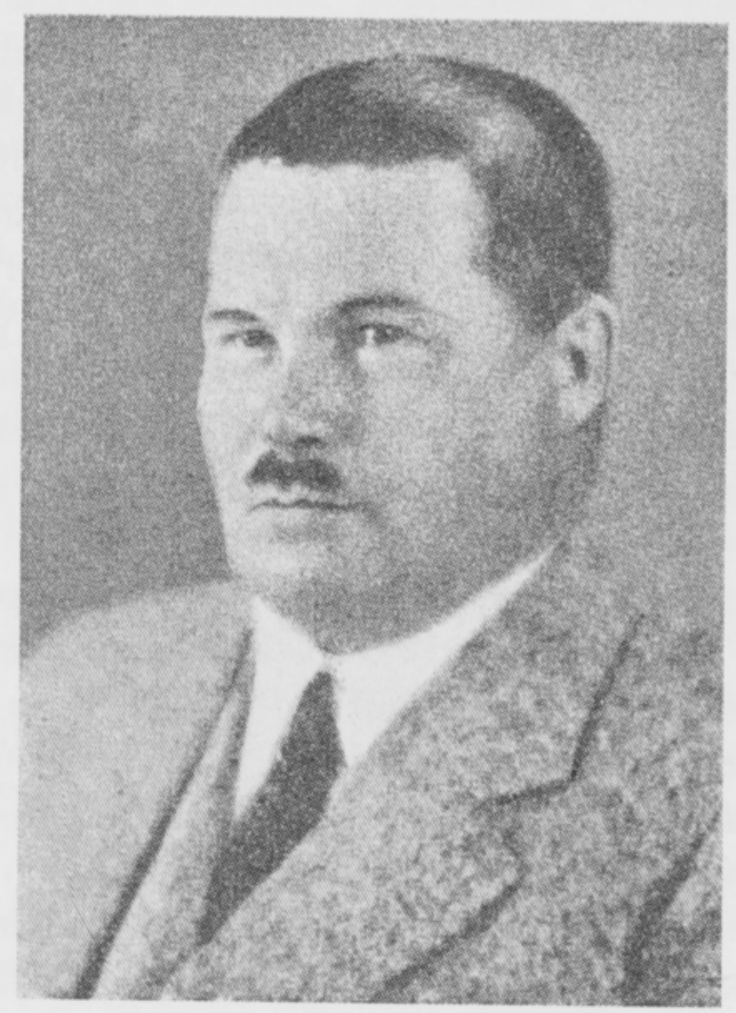

\title{
PEKKA AARON KOKKONEN
}

\author{
*8. 8. $1887-\doteqdot 16.2 .1951$.
}

Helmikuun 16 p:nä kuoli Helsingissä teknillisen korkeakoulun maanjako- ja katasteritekniikan professori PekKa Aaron Kokkonen, joka oli syntynyt Iisalmella elokuun 8 p:nä 1887. Mentyään verraten myöhään oppikouluun hän tuli ylioppilaaksi 1910 ja aloitti opintonsa teknillisessä korkeakoulussa, jossa hän suoritti maanviljelysinsinööritutkinnon 1916. Tämän tutkinnon ympärille hän sitten »keräsi» lukuisasti lisätutkintoja: metsänhoitajatutkinto 1918, filosofian kanditaattitutkinto 1922, filosofian lisensiaattitutkinto 1924, maatalous- ja metsätieteen tohtoritutkinto 1927 ja maanmittausinsinööritutkinto 1931. Tuskin on toista henkilöä, joka Suomessa olisi suorittanut niin monta eri korkeakoulututkintoa. Nämä tutkinnot muodostivat kuitenkin kiinteän kokonaisuuden, jossa hänen ensiksi suorittamansa maanviljelysinsinööritutkinto aineyhdistelmänsä puolesta muodosti rungon sisältäen peruskurssin useimmista hänen myöhemmin suorittamistaan tutkinnoista. 
Näin saavutettu laaja oppineisuus maa- ja metsätalouden eri kysymyksissä muodosti hyvän pohjan sille aineelle, jota hän myöhemmin joutui professorina hoitamaan. Tietojaan Kokkonen täydensi opintomatkoillaan Saksaan, Ruotsiin, Hollantiin ja Sveitsiin.

Varsinaisen elämäntyönsä Kokkonen suoritti korkeakouluopet t aj a n a. Helsingin yliopistossa hän oli metsäteknologian opettajana v. 1917, maanviljelystekniikan assistenttina vuodesta 1922 vuoteen 1936 sekä dosenttina vuodesta 1929 vuoteen 1950, jolloin sairautensa vuoksi joutui tehtäviään vähentämään. Maanviljelystalouden avoinna ollutta professorin virkaa hän hoiti vuosina 1929 1930. Hänet katsottiin päteväksi myös maanviljelysopin professorin virkaan 1932. Teknillisessä korkeakoulussa hän hoiti maanviljelysopin ylimääräistä opettajan virkaa 1933 ja nimitettiin maanjako- ja katasteritekniikan professorin virkaan 1936, missä toimessa hän oli kuolemaansa saakka. Tämän ohella hän hoiti tilapäisesti mm. käytännöllisen jakotekniikan erikoisopettajan tointa.

Opetustoimessaan professori Kokkosella oli laajojen perustietojensa ohella apuna talonpoikainen käytännöllisyyden taju. Varsinaisen pääaineensa, maanjakotekniikan opetuksessa hän erikoisesti korosti tilusjakojen käytännöllisyyttä ja niitä perustekijöitä, joista yksityisen maatilan taloudellisuus riippuu. Hänen opetuksensa tapahtui Jeppoiseen savolaiseen tyyliin. Hän oli myös herätteenantajana alansa tutkimustoiminnassa $\mathrm{mm}$. ohjaten parin väitöskirjan tekoa.

Kokkonen toimi virallisena vastaväittäjänä seuraavien väitöskirjojen tarkastuksessa: 1929 maat.metsät. kanditaatti Antti Vesikiven väitöskirja "Suon savetuksen ja hiekoituksen taloudellisesta kannattavaisuudesta», 1943 maanmittausinsinööri Mauno Kajanmaan väitöskirja "Topografisen kartoituksen perusteista", 1944 maanmittausinsinööri Väinö Suomaan väitöskirja "Havaintoja viljelyskunnon tilistä maanjaossa», 1946 maanmittausinsinööri Eero Salosen väitöskirja "Kaupunkimittauksen tehtävistä ja tarkkudesta», 1947 maanviljelysinsinöörı Matti Wäreen väitöskirja »Maan vesisuhteista ja viljelyskasvien sadoista Maasojan vesitaloudellisella koekentällä vuosina 1939-1944», 1948 maanmittausinsinööri Arvid Viialan väitöskirja "Uusjaon vaikutuksesta jakokunnan maatalouteen» ja 1948 maanmittausinsinööri Paavo Lapin väitöskirja "Pelto- ja metsätilusten arvosuhteesta maanjaossa”

Muista Kokkosen suorittamista tehtävistä mainittakoon, että vuosina 1918 1919 hän toimi asutushallituksen insinöörinä ja vuosina 19191923 ylimääräisenä maanviljelysinsinöörinä maataloushallituksessa. Vuosina 1928-1931 Kokkonen hoiti hänen aloitteensa johdosta alullepantuja maataloushallituksen kulttuuriteknillisiä tutkimuksia. Vuosina 1931— 1936 hän toimi ma a mitta usinsinööri n̈ suorittaen lähinnä uusjako- ja asutustoimituksia Uudenmaan, Hämeen ja Oulun lääneissä. Tämän lisäksi Kokkosta käytettiin usein asiantuntijana alaansa liittyvissä kysymyksissä.

Erikoisen huomion arvoinen on Kokkosen tiet e ellinen to iminta. Aluksi se suuntautui pääasiassa kulttuuriteknillisiin kysymyksiin ja myöhemmin maanjakoon liittyviin kysymyksiin. Hänen väitöskirjansa käsitteli viemärin kuntoon vaikuttavia tekijöitä. Muista maatalouden vesirakennukseen liittyvistä kysymyksistä mainittakoon hyödyn arviointia yhteisissä kuivatusyrityksissä koskevat 
samoinkuin kuivatuksen aiheuttamaa suon painumista koskevat tutkimukset. Myös puiden juuristoa ja metsän kasvua ojitetuilla soilla Kokkonen tutki. Maan routaantumista ja roudan rakennetta koskevissa tutkimuksissa Kokkonen oli uranuurtaja ja johtavia nimiä koko maailmassa. Routatutkimusten yhteydessä hän suoritti myös viljelyskasvien juuritutkimuksia selvitellen erikoisesti juurien venytyskestävyyttä ja sen vaikutusta talvehtimiseen. Ansiokas, monia käytännöllisiä ja itsenäisiä ajatuksia sisältävä on hänen laatimansa maanmuokkausta koskeva oppikirja. Maanjakotekniikan alaan kuuluvista tutkimuksista mainittakoon tiluslajeja, jyvitystä, tilusrajojen sovitusta ja maan arvoa koskevat tutkimukset. Hän suoritti myös tutkimuksia maatilan muodon ja tilusten sijainnin vaikutuksesta maatilan talouteen. Vuonna 1950 hän sai Suomen Akatemian vanhempain tieteenharjoittajain apurahan tutkiakseen Lounais-Suomessa tavattavia tilamuotoja, mutta kuolema keskeytti nämä työt. Tutkimuksissaan Kokkosella oli terävä silmä valitsemaan aiheet alan keskeisistä kysymyksistä sekä havaitsemaan näissä aiheissa oleelliset seikat samalla, kun hän usein valotti tutkittavaa kysymystä kokonaan uudelta näkökulmalta.

Kokkonen oli myös jäsenenä useissa ti e te e 11 is is sä j a a m matillisissa yhdistyksissä kuten Suomen maataloustieteellisessä, metsätieteellisessä, maantieteellisessä, eläin- ja kasvitieteellisessä sekä maanmittaustieteellisessä seurassa. Suomalaisessa Tiedeakatemiassa hän oli jäsenenä vuodesta 1943.

Kokkosen ulkonaisesti karulta vaikuttavaan olemukseen liittyi syvällinen kulttuuripyrkimys. Laajan ammattiasioihin kohdistuneen lukeneisuuden ohella hän harrasti muunkinlaista kirjallisuutta, mm. hän oli erikoisesti syventynyt Euroopan historiaan. Saunan ystävänä hän myös oli tunnettu. Savolaisena hänessäpulppusi omalaatuinen sattuva huumori. 


\title{
PEKKA AARON KOKKONEN
}

\author{
* 8. 8. $1887-\dagger 16.2 .1951$.
}

Am 16. Februar 1951 starb in Helsinki Pekka Aaron Kokkonen, Professor für Feldteilungs- und Katastertechnik an der Technischen Hochschule. Am 8. August 1887 wurde er in Iisalmi geboren. Nach verhältnismässig spätem Besuch der höheren Schule bestand er 1910 das Abiturientenexamen; danach studierte er auf der Technischen Hochschule, wo er 1916 Kulturingenieur wurde. Um das entsprechende Examen herum »sammelte» er zahlreiche weitere Examina: Oberförsterexamen 1922, Cand. phil. 1922, Lic. phil. 1924, Dr. agr. et forest. 1927 und Vermessungsingenieur 1931. Kaum gibt es in Finnland sonst jemanden, der so viele Hochschulexamina abgelegt hätte. Diese Examina bildeten jedoch ein geschlossenes Ganzes, in dem das von ihm zuerst bestandene Kulturingenieurexamen durch seine Fachzusammenstellung den Kern ausmachte, indem es den Grundkursus von den meisten der späten von ihm abgelegten Examina enthielt. Die so erlangre umfassende Gelehrsamkeit in den verschiedenen Fragen der Land- und Forstwirtschaft bildete eine gute Grundlage für das Fach, das er später als Professor zu versehen hatte. Seine Kenntnisse vervollständigte Kokkonen auf Studienreisen nach Deutschland, Schweden, Holland und der Schweiz.

Seine eigentliche Lebensarbeit leistete Kokkonen als Hochschulelehrer. An der Universität Helsinki war er Lehrer der Forsttechnologie 1917, Assistent der Kulturtechnik 1922-1936 sowie Dosent 1929-1950, als er seiner Krankheit wegen seine Aufgaben zu vermindern hatte. Die vakant gewesene Professur der Agrikulturwirtschaft versah er 1929-1930. Auch wurde er 1932.als kompetent für die Professur der Landbaulehre erachtet. An der Technischen Hochschule versah er das Amt eines nicht etatmässig angestellten Lehrers der Landbaulehre und wurde 1936 zum Professor für Feldteilungs- und Katastertechnik ernannt, welches Amt er bis zu seinem Tode innehatte. Daneben war er vorübergehend unter anderem als Speziallehrer der praktischen Feldteilungstechnik tätig.

In seiner Lehrtätigkeit war Professor Kokkonen neben seinen umfassenden Grundkenntnissen ein bäuerlicher praktischer Sinn von Nutzen. Beim Unterricht in seinem eigentlichen Hauptfach, Feldteilungstechnik, betonde er besonders die praktische Seite der Feldteilung und die Faktoren, auf denen die Wirtschaftlichkeit des einzelnen Landguts beruht. Sein Unterricht ging in der für Savo bezeichnenden gemütlichen Weise vor sich. Auch gab er Anregungen in der Forschungsar- 
beit auf seinem Gebiet, indem er unter anderem beim Zustandekommen von ein paar Dissertationen Anleitung gab.

Kokkonen wirkte als offizieller Opponent bei der Prüfung folgender Dissertationen: 1929 Cand. agr. et forest. Antti Vesikivi: „Suon savetuksen ja hiekoituksen taloudellisesta kannattavaisuudesta», 1943 Vermessungsingenieur Mauno Kajanmaa: "Topografisen kartoituksen perusteista», 1944 Vermessungsingenieur Väinö Suomaa: „Havaintoja viljelyskunnon tilistä maanjaossa», 1946 Vermessungsingenieur Eero Salonen: "Kaupunkimittauksen tehtävistä ja tarkkuudesta», 1947 Kulturingenieur Matti Wäre: "Maan vesisuhteista ja viljelyskasvien sadoista Maasojan vesitaloudellisella koekentällä vuosina 1939-1944», 1948 Vermessungsingenieur Arvid Viiala: "Uusjaon vaikutuksesta jakokunnan maatalouteen», und 1948 Vermessungsingenieur Paavo Lappi: "Pelto- ja metsätilusten arvosuhteesta maanjaossa».

An sonstigen von Kokkonen geleiteten Aufgaben sei angeführt, dass er 19181919 als Ingenieur der Siedlungsverwaltung und 1919-1923 als nicht etatmässig angestellter $\mathrm{Kulturingenieur}$ bei der L a dwirtschaftsverwaltung wirkte. In den Jahren 1928-1931 leitete Kokkonen die auf seine Anregung eingefürhten kulturtechnischen Untersuchungen der Landwirtschaftsverwaltung. In den Jahren 1931-1936 wirkte er als Vermessungsing en i e r, in erster Linie Flurbereinigungs- und Siedlungsvorhaben in den Provinzen Uusimaa, Häme und Oulu durchführend. Ausserdem trat Kokkonen oft als Expert bei einschlägigen fragen auf.

Besonders beachtenswert ist Kokkonens wis sens chaft lich e Tätigk e i t. Anfangs wandte sie sich hauptsächlich kulturtechnischen Fragen und später mit der Bodenteilung zusammenhängenden Problemen zu. Seine Dissertation behandelte die auf den Zustand der Abflussgräben einwirkenden Bedingungen. An sonstigen mit dem landwirtschaftlichen Wasserbau verbundenen Fragen seien die Untersuchungen über, die Veranschlagung des Nutzens bei gemeinsamen Entwässerungsprojekten wie auch über die durch Entwässerung verursachte Moorsackung angeführt. Auch hat Kokkonen die Bewurzelung der Bäume und den Waldwuchs auf entwässerten Mooren untersucht. In der Untersuchungen über das Auffrieren des Bodens und die Struktur des Bodenfrostes war Kokkonen Bahnbrecher und einer der führenden Namen in der ganzen Welt. In Zusammenhang mit den Bodenfrostuntersuchungen erforschte er auch die Wurzeln der Kulturpflanzen, insbesondere die Zugfestigkeit der Wurzeln und ihre Wirkung auf die Überwinterung aufklärend. Verdienstvoll, reich an praktischen und selbständigen Gedanken ist das von ihm verfasste Lehrbuch der Bodenbearbeitung. Von den zum Gebiet der Feldteilungstechnik gehörenden Untersuchungen seien die über die Bonitierung, den Ausgleich der Flurgrenzen und den Bodenwert erwähnt. Auch führte er Untersuchungen über den Einfluss der Landgutform und der Grundstücklage auf die Wirtschaft des Landguts aus. Im Jahre 1950 erhielt er von der Finnischen Akademie der Wissenschaften ein Stipendium für ältere Gelehrte, um die in Südwestfinnland anzutreffenden Flurformen zu erforschen, aber der Tod unterbrach diese Arbeiten. Bei seinen Untersuchungen hatte Kokkonen ein scharfes Auge, den Stoff in den Kernfragen des 
Gebiets zu suchen sowie die darin wesentlichen Umstände zu erkennen, indem er oft die zu erforschende Frage von einem ganz neuen Gesichtspunkt aus beleuchtete.

Auch war Kokkonen Mitglied in vielen wissenschaftlich en $\mathrm{und}$ fachlichen Vereinigungen wie in der Landwirtschaftwissenschaftlichen, der Forstwissenschaftlichen, der Geographischen, der Zoologischen und Botanischen sowie der Vermessungswissenschaftlichen Gesellschaft Finnlands. Mitglied der Finnischen Akademie der Wissenschaften war er seit 1943.

Mit Kokkonens äusserlich anspruchlsos wirkendem Wesen war ein tiefes Kulturstreben vereint. Bei umfassender Gelehrsamkeit in fachlichen Dingen war er auch begeistert für sonstiges Schrifttum, unter anderem war er ausführlich unterrichtet in europäischer Geschichte. Als Saunafreund war er ebenfalls bekannt. In Savo beheimatet, sprudelte in ihm ein eigenartiger treffender Humor.

\section{Pentti Kaitera.}

PROFESSORI PEK K A A A RON KOKKOSE N KIRJALLINEN TOIMINTA. SCHRIFTEN VON PROFESSOR PEK KA A A R N KOK KONEN.

1919 Rajojen sijoituksesta maanjakotoimituksissa. Asuttaja, n:o 4-5, p. 60-65, Helsinki.

1921 Laatikkosalaojituksesta. Teknillinen Aikakauslehti, n:o 5-6, p. 434-441, Helsinki.

1923 Tutkimuksia viemärien kuntoon vaikuttavista seikoista (väitöskirja). Acta Forestalia Fennica, 27. 3, p. 1-200, Helsinki.

- Hyödyn arvioimisesta kuivatusyrityksissä. Suomen Maataloustiet. Seuran julk. 8 B, p. 1-64, Helsinki.

— Viemäriverkoista. Teknillinen Aikakauslehti, n:o 12, p. 469-496, Helsinki.

- Beobachtungen über das Wurzelsystem der Kiefer in Moorböden. Acta Forestalia Fennica, 25, p. $1-61$, Helsinki.

1924 Maanpaineesta. Teknillinen Aikakauslehti, n:o 2, p. 99 -101, Helsinki.

1925 Kulttuuriteknillisestä tutkimustyöstä. Teknillinen Aikakauslehti, n:o 3, p. 137-140, Helsinki. 1926 Beobachtungen über die Struktur des Bodenfrostes. Acta Forestalia Fennica, 30. 3, p. 1-56, Helsinki.

- Kymijoen perkauksesta johtuva maanarvon nousu, Suomen Maataloustiet. Seuran julk, 11, p. 1-46, Helsinki.

1927 Rukiin talvehtimisen ja sen juurien venyvyyden ja venytyskestävyyden välisestä suhteesta, Valt. Maatalouskoetoim. julk., n:o 11, p. 1-34, Helsinki.

— Roudan rakenteesta ja sen merkityksestä kasvinviljelyksessä. Maatalous, n:o 1 p. 199-206, Porvoo.

1928 Havaintoja Hollantiin ja Sveitsiin tehdyltä kulttuuriteknilliseltä opintomatkalta ja mietteitä sen johdosta. Maanmittaus, II vihko, p. 227-234, Helsinki.

1929 Über das Verhältnis der Winterfestigkeit des Roggens zur Dehnbarkeit und Dehnungsfestigkeit seiner Wurzeln." Acta Forestalia Fennica, 33 3, p. 1-50, Helsinki.

- Maanviljelysteknillisestä tutkimustyöstä ja sen edistämisestä. Maataloustiet. Aikakauskirja, n:o $1-2$, p. $60-72$, Helsinki .

- Beobachtungen über die Beziehungen zwischen der Grundwassertiefe und dem Waldwachstum auf einem kanalisierten Moore, Acta Forestalia Fennica, 34. 29, p. 1-8 Helsinki.

— Roudan rakenteesta ja siihen vaikuttavista seikoista. Teknillinen Aikakauslehti, n:o 19, p. 199_206, Helsinki. 
1930 Hakamaat ja hakamaametsät. Maa ja metsä, IX. 2, p. 519-525, Porvoo.

- Havaintoja kylvö- ja siemennystavan vaikutuksesta rukiin talvehtimiseen. Maataloustiet. Aikakauskirja, n:o 2, p. 49-59, Helsinki.

- Beobachtungen über die durch den Bodenfrost verursachte Hebung der Erdoberfläche und in der Fröstschicht befindlicher Gegenstände. Maataloustiet. Aikakauskirja, n:o 3, p. 83-100, Helsinki.

— Lausunto joenpurkauskomissionille. Komiteamietintö, n:o 6, Helsinki.

- Havaintoja roudan aiheuttamasta maanpinnan ja routakerroksessa olevien esineiden kohoamisesta. Teknillinen Aikakauslehti, n:o 12, p. 731_739, Helsinki.

1931 Untersuchungen über die Wurzeln der Getreidepflanzen. I. Die Wurzelform, ihr Bau, ihre Aufgabe und Lage im Wurzelsystem. Acta Forestalia Fennica, 37. 2, p. 1-144, Helsinki.

- Tutkimuksia kuivatuksen aiheuttamasta turvekerrosten painumisesta. Valt. maatalouskoet. julk., n:o 40, p. $1-78$, Helsinki.

- Edullisin tilamuoto, Maanmittaus, p. 195- 211, Helsinki.

- Roots ond Root-systems of Cocksfoot (Dactylis glomerata). Maataloustiet. Aikakauskirja, 2. vihko, p. $33-37$, Helsinki.

1932 Rajasovituksista maanjakotoimituksissa. Maanmittaus, 3. ja 4. vihko, p. 1—38, Helsinki.

- Om skifteslinjernas placering vid skiftesläggning. Svensk Lantmäteritidskrift, p. 1-27. Stockholm.

- Kulttuuriteknilliset työt maanjakojen yhteydessä. Maanmittaus, 4. vihko, p. 1-18, Helsinki.

- Havaintoja muokkauksien vaikutuksesta maan muutamiin fysikaalisiin olosuhteisiin. Maataloustiet. Aikakauskirja, p. 117-132, Helsinki.

— Havaintoja Ruotsin matkalta. Suomen Maanmittari-Yhdist. Aikakauskirja n:o 5—7, p. 197_-203, Helsinki.

— Kuivatukset maanjakojen yhteydessä. Ibid., n:o 4 ja 9, p. 117-133 ja 317 - 322 .

1933 Tilusten etäisyyden vaikutus työmenekkiin. Maanmittaus, p. 135-154. Helsinki.

1934 Maanjakotoimituksissa syntyvien palstojen muodosta metsätalouden kannalta. Acta Forestalia Fennica, 40, p. 673-696, Helsinki.

— Tiluslajit ja niiden jyvittäminen. Käsikirjoitus, maanmittaushallituksen määräyksestä tehty tutkielma.

- Tilusmittauksessa huomattavat muut alueet. Suomen Maanmittari-Yhdist. Aikakauskirja, n:o 2, p. 51-54, Helsinki.

1937 Huomioita uusjaon tuottamasta hyödystä ja sen määräämisestä. Ibid., n:o 10—11, p. 233 -239.

1938 Jyvityksessä tapahtuva tilusten maaperän tutkiminen. Ibid. n:o 12, p. 245-257.

1939 Maan arvioimisessa käytetyistä jyvälukumenetelmistä. Ibid., n:o 7—9, p. 177-182

1940 Muunnettu peltohehtaari. Ibid., n:o 5-6, p. $49-52$.

- Tiluslajit. Maanmittaushallituksen julkaisuja, n:o 30, p. 1-67 Helsinki.

- Maan »käypä hinta» Nurmijärven kunnassa vuosina 1934-38. Maataloustiet. Aikakauskirja, p. 98 - 141, Helsinki.

- Maan »käypä hinta» Nurmijärven kunnassa vuosina 1934-38. Suomen Maanmittari-Yhdistyksen Aikakauskirja, n:o $7-9$, p. 77-124, Helsinki.

— „Käypä hinta» ja »järkevän ostajan hinta». Ibid., n:o 5-6, p. 61-65.

— Eräitä huomioita tilamuodon vaikutuksesta maatilan talouteen. Ibid., n:o 10_11, p. 156-174.

- Maatilan muodon osoittajista eli muotoluvuista. Ibid., n:o 12, p. 183-196.

1941 Piirteitä yhdistyksemme ja aikakauskirjamme 50-vuotistaipaleelta. Ibid., n:o 5-7, p. 91-145.

- Iakttagelser rörande lägenhetsformens inverkan på lantgodsens ekonomi. Svensk Lantmäteritidskrift, Stockholm.

- Mietteitä uuden maajaon suorittamisesta Karjalan kannaksella. Suomen Maanmittari-Yhdistyksen Aikakauskirja n:o 12, p. 435-459, Helsinki.

— Uusjaot Etelä-Saksassa, Ibid., n:o 8, p. 456-471, Helsinki. 
1942 Maan hinnoittelusta. Maatalousministeriön asutusasiainosaston julkaisuja, n:o 4, Helsinki.

— Beobachtungen über den Bodenfrost des Winters 1941-42. Acta Forestalia Fennica, 50.22, p. 1-11, Helsinki.

- Havaintoja viime talven roudasta ja sen sulamisesta sekä sen vaikutuksesta viljelykseen. Maataloustiet. Aikakauskirja, p. $80-110$, Helsinki.

— Roudasta ja sen vaikutuksesta peltoviljelykseen. Maatalous, p. 279-286, Forssa.

- Maanmittausopetuksen uusiminen Teknillisessä korkeakoulussa vuonna 1942 ja sen vertailu aikaisempaan. Suomen Maanmittari-Yhdist Aikakauskirja, n:o 9-12, p. 119-131, Helsinki.

- Maanmuokkaus, p. 1-180, Helsinki.

- Kuluneen talven routa ja sen sulaminen, Pellervo, n:o 8, p. 301, Helsinki.

1943 Maanmittausinsinöörien apulaiskysymys. Suomen Maanmittari-Yhdist. Aikakauskirja, n:o 9, p. 201-220, Helsinki.

— Eräs henkilökohtainen vero n. 200 vuotta sitten. Ibid., n:o $4-5$, p. $96-100$.

— Kiinteistöjen hallinto, Maatalous, n:o 4, p. 90-95 ja 9, p. 197-201 Forssa.

1944 Roudasta ja sen merkityksestä. Suom. Tiedeakatemia, Esitelmät ja pöytäkirjat, p. $135-158$, Helsinki.

1945 Eri maalajeista ja niiden merkityksestä maatilan taloudessa. Suomen Maanmittari-Yhdist. Aikakauskirja, n:o 3, p. 37-53, Helsinki.

_ Viljelysmaiden arvioimisesta Saksassa vuonna 1934. Ibid., n:o 11, p. 254 262, Helsinki.

- Über den Bodenfrost und seine Bedeutung. Sonderabdruck aus den Sitzungsber. der finn. Akad. der Wissenschaften 1944, p. 153-180, Helsinki.

1946 Huomioiła tilojen muodostamisesta nykyisessä asutustoiminnassa. Suomen Maanmittari-Yhdist. Aikakauskirja, n:o 4, p. 103-110, Helsinki.

- Uusjaontapaisia kiinteistömuodostamiskokeita Pohjois-Ruotsissa. Ibid., n:o 5, p. 127-136,

- Maalaistalojen sijoitusprobleemeja. Ibid., n:o 5, p. 146-155.

- Havaintoja maanhankintalain toimeenpanosta eri puolilla Suomea. Ibid., n:o 11. p. $319-346$.

- Havaintoja maatilojen muodosta Vakka-Suomessa. Ibid., n:o 5-6, p. 203-214, Tampere.

1947 Matkahavaintoja Keski-Ruotsissa. Maatalous n:o 8, p. $111-115$, Forssa.

1951 Maanmittaus ja maanjaot. Suomen maantieteen käsikirja, p. 358 - 363, Helsinki. 